\title{
Troublesome Trimes: Potential cryptic speciation of the Trimeresurus (Popeia) popeiorum complex (Serpentes: Crotalidae) around the Isthmus of Kra (Myanmar and Thailand)
}

\author{
DANIEL G. MULCAHY ${ }^{1,5}$, JUSTIN L. LEE ${ }^{2,3}$, ARYEH H. MILLER ${ }^{2,4} \&$ GEORGE R. ZUG ${ }^{2}$ \\ ${ }^{I}$ Global Genome Initiative, National Museum of Natural History, Smithsonian Institution, Washington, DC, 20013 USA \\ ${ }^{2}$ Department of Vertebrate Zoology, National Museum of Natural History, Smithsonian Institution, Washington, DC, 20013 USA \\ ${ }^{3}$ College of Computer, Mathematical and Natural Sciences, University of Maryland, College Park, MD, 20742 USA \\ ${ }^{4}$ Department of Biology, University of North Carolina Asheville, Asheville, NC 28804. \\ ${ }^{5}$ Corresponding author. E-mail: MulcahyD@si.edu
}

\begin{abstract}
The taxonomic identity of the Trimeresurus (Popeia) popeiorum complex from the Isthmus of Kra and to the north was investigated. Several studies over the last decade have produced several specimens and associated mtDNA sequence data for a variety of individuals of the T. popeiorum and "T. sabahi" complexes. Here, we combine four mitochondrial genes (12S, 16S, ND4, and CytB) from all available specimens in GenBank with the addition of five new specimens collected from the mainland, Tanintharyi Region of Myanmar. Maximum Likelihood and Bayesian analyses identified that $T$. popeiorum sensu lato is paraphyletic with two geographically distinct clades: a northern clade representing populations from northern Myanmar, Laos and northern Thailand and a southern clade representing samples from the Tanintharyi Region and adjacent west Thailand. While the two clades have considerable genetic distance, they appear to be morphologically identical, leading to the hypothesis that the southern clade represents a cryptic, undescribed species. Because they appear to be cryptic species and the limitation of only five specimens from the southern lineage, this does not permit us to formally describe the new species. In accordance to past molecular studies, we uncovered paraphyly and lack of genetic support for the validity of taxa within the T. sabahi complex. However, we suggest recognizing these populations as subspecies within T. sabahi.
\end{abstract}

Key words: Cryptic speciation, Myanmar, Southeast Asia, Subspecies, Tanintharyi Region, Thailand, Trimeresurus

\section{Introduction}

Often times new species are described based on few individual specimens available, sometimes only from the type series, which can be problematic for interspecific comparisons. This can be particularly problematic in species with sexual dimorphism and/or from cryptic species complexes. Additionally, sequences in GenBank are often not represented by voucher specimens and sequences can be misidentified, which confounds resolution of relationships. Cryptic species, morphologically indistinguishable but genetically and/or reproductively isolated (Bickford et al. 2006; Jörger et al. 2013), can confound taxonomic matters even further (Funk et al. 2012). Molecular sequencing methods can be extremely useful for determining cryptic species (Hebert et al. 2004), particularly in groups with limited samples for morphological comparisons.

Southeast Asian Green Pitvipers (Genus: Trimeresurus) are notoriously difficult to classify. Despite the abundance of specimens in museum collections for some species, morphological conservatism in the genus makes taxonomic studies challenging and some species are only represented by few museum specimens. Such limited samples have resulted in misidentifications within the genus (e.g. Orlov \& Helfenberger, 1997) that were subsequently corrected by others (Malhotra \& Thorpe 2000; Giannasi et al. 2001; Tillack et al. 2003). Nevertheless, species diversity in Trimeresurus is likely underestimated, as detailed examination of several groups has revealed undescribed or revalidated species (Vogel et al. 2004; David et al. 2006; Grismer et al. 2006; David et 
al. 2009; Guo \& Wang, 2011; Malhotra et al. 2011; Sumontha et al. 2011; Vogel et al. 2014a; Vogel et al. 2014b). Molecular phylogenetic analyses also have identified cryptic diversity in some species (Guo et al. 2015; Thorpe et al. 2015).

Recent (2015-2016) rapid assessment surveys in southern Tanintharyi Region, Myanmar by one of us (DGM) yielded three specimens, which we assigned to the subgenus Popeia (Malhorta \& Thorpe, 2004), specifically to Trimeresurus popeiorum Smith, 1937. Recently, several new species in this and the T. sabahi complexes have been described (e.g. Vogel et al. 2004; Grismer et al. 2006; David et al. 2009). Additional studies using mitochondrial DNA (mtDNA) sequence data have attempted to unravel these complexes (Malhorta and Thorpe 2004; Sanders et al. 2006). A recent study claims to resolve most taxonomic issues for this group (Wostl et al. 2016); however, a comprehensive analysis has yet to be conducted, and questions remain as to what species occur in the Tanintharyi.

Briefly, the Popeia subgeneric group occurs from northern India to southern China (Guo et al. 2015) southward through Myanmar, Thailand, Indochina, and Malay Peninsula into Borneo and Sumatra. The type species, Trimeresurus popeiorum, was described in 1937 by Malcolm A. Smith without any precise type locality or type specimen. This was subsequently corrected by Taylor \& Elbel (1958). Later, Regenass \& Kramer (1981) described two new subspecies (T. p. barati and T. p. sabahi) in the complex. In 2004, Malhotra \& Thorpe performed a revision of Southeast Asian Trimeresurus. Their study included both morphological (hemipenes, scalation) and genetic (mtDNA) characters. They suggested the subdivision of the Trimeresurus species into several "new" genera. One of these genera was Popeia for T. popeiorum. In the same year, Vogel et al. (2004) revised T. popeiorum and, on the basis of morphological characters, recognized two new species in Peninsular Malaysia: Trimeresurus fucatus Vogel, David \& Pauwels, 2004 in southern Thailand and Peninsular Malaysia and Trimeresurus nebularis Vogel, David \& Pauwels, 2004 restricted to the Cameron Highlands of Peninsular Malaysia. They also elevated Trimeresurus barati (Regenass and Kramer, 1981) for the Sumatran populations and T. sabahi (Regenass and Kramer, 1981) for the "popeiorum" of Borneo. This new taxonomy resulted in the distribution T. popeiorum being the northern portion of the previous Southeast Asian-wide range but also identified the populations as far south as Myeik, (Tanintharyi, Myanmar), as T. popeiorum. Their distributional concept, however, disagreed with their identification of several specimens, i.e., they considered a female BMNH 1924.5.20.38 from "Taok Plateau, Tenasserim" (now Mt. Pya Taung, Tanintharyi, Myanmar) as T. popeiorum, and two males: BMNH 56.5.6.105 from Myeik, Tanintharyi, Myanmar and BMNH 1940.3.9.43 from Kanmaw Kyun Island (= Kisseraing Island), Tanintharyi, Myanmar as T. fucatus. Subsequently, Pauwels and Chan-ard (2006) identified Trimeresurus (Popeia) from Keang Krachan National Park, Thailand as T. fucatus.

Sanders et al. (2006) using an expanded molecular and morphological data from Malhotra and Thorpe (2004), defined two clades within the Popeia complex. The Northern Clade contained all specimens north of the Isthmus of Kra and one specimen (B467) near Phang-nga (south Thailand). The Southern Clade contained all specimens further south in the Malay Peninsula and the islands of Indonesia. Sanders et al. (2006) recommended a more conservative taxonomy, placing all Popeia species from the Sundaland region into T. sabahi, except for $T$. nebularis and retaining T. popeiorum for specimens north of the Malay Peninsula. Sanders et al. (2006) also examined the morphology of a specimen from Tanintharyi, identified by Vogel et al. (2004) as T. fucatus (BMNH 1940.3.9.43), and it was identified as part of the "Northern Clade". However, they did not examine any other individuals from Tanintharyi and provided no meristic data from the BMNH specimen. They included uncatalogued specimens from Phetcheburi Province (AMB52; B34) in their statistical sample and identified them as $T$. popeiorum; these specimens were paraphyletic with respect to other $T$. popeiorum specimens in their molecular phylogenetic analysis. Another uncatalogued specimen from Phang-nga Province, Thailand (B467) was also included in the northern clade, and this inclusion also rendered T. popeiorum paraphyletic.

The taxonomy suggested by Sanders et al. (2006) remains controversial. Subsequent studies focusing on the Popeia subgenus continue to follow the taxonomy suggested by Vogel et al. (2004). Grismer et al. (2006) described T. buniana from Pulau Tioman Island off the coast of Peninsular Malaysia. David et al. (2009) described northern Sumatran specimens as T. toba and recommended that the genus Popeia (Malhotra \& Thorpe, 2004) be used as a subgenus in order to preserve the definitive nature of the genus Trimeresursus. David et al. (2011) expanded on this recommendation and identified the nucleospecies (= type species) of the genus Trimeresurus as T. viridis Lacépède, 1804 (= T. insularis Kramer, 1977) and officially recognized all genera proposed by Malhotra \& Thorpe (2004) as subgenera with the exception of Ovophis and Protobothrops. Based on morphometrics, Sumontha et al. (2011) described T. phuketensis, a species endemic to Phuket Island, Thailand. It is unique among Popeia in that both 
males and females contain a bicolored postocular and ventrolateral stripe. Most recently, Wostl et al. (2016) added molecular data for two previously un-sampled taxa (T. barati and T. toba), but used only two (of four) mtDNA genes used by Sanders et al. (2006). Wostl et al. (2016) also identified all Popeia from the Sundaland biogeographic region as T. sabahi, including T. buniana and T. toba. However, they did not evaluate the taxonomic status of T. phuketensis as there were no genetic sequences available; they also did not include the south (B467) and west (AMB52; B34) Thai samples of T. popeiorum - which rendered the species paraphyletic in Sanders et al. (2006).

In spite of the large number of taxonomic studies focused on the Popeia subgenus, the identity of populations in the Tanintharyi region and the Isthmus of Kra remains uncertain. No comprehensive molecular dataset has been used to examine the affinities of the green Trimeresurus from this area. Here, we use recently collected specimens, augmented with additional California Academy of Sciences (CAS) specimens from the Tanintharyi Region, to determine which species occur in this region. We investigate the identity and relationships of these specimens with those in adjacent areas using molecular and morphological data by including all available specimens available in GenBank, all four mtDNA loci, and morphological data provided in previous studies.

\section{Material and methods}

All three specimens from the 2015-2016 survey were deposited in the National Museum of Natural History, Smithsonian Institution (USNM). The first specimen (USNM 587588) was collected in Lenya in May 2015. Two specimens, both adult females, (USNM 587918 and USNM 587919) were collected in Ywahilu in May 2016. One of these (USNM 587918) was found dead on the road and partially skeletonized, hence unavailable for morphological study. However, tissue samples were taken and the specimen is vouchered as a skeleton. Two specimens (a juvenile female USNM 587920, adult male USNM 587921) collected from Kawthaung, Tanintharyi, Myanmar, were included in the morphological analysis. Our molecular analyses also included specimens from the California Academy of Sciences: Dawei Township (a male CAS 245932) and Kawthaung (a female CAS 247754).

Tissue samples were taken from the liver and heart and preserved in salt-saturated DMSO/EDTA buffer for genetic analyses. Extractions of genomic DNA were conducted on small pieces of liver or muscle tissue and run on an Auto-Genprep 965 (2011 AutoGen, Inc.), using standard phenol manufacturer protocols. Genomic DNA was eluted in $100 \mu \mathrm{l}$ of AutoGen R9 re-suspension buffer. We sequenced four mitochondrial genes CytB, ND4, 16S and 12S. Primers used for each gene are identified in Table 1. Cycle-sequence reactions were performed in both directions, using the PCR primers using BigDye Terminator v3.1 Cycle Sequencing Kit's in $0.25 \times 10 \mu 1$ reactions run on and ABI3730 Sequencer (2011 Life Technologies) using the 950 chemistry. Raw trace files were edited in Geneious 9.1.5 (Biomatters Ltd 2005-2016), complementary strands were aligned, edited, and inspected for translation. All sequences were deposited in GenBank under accession numbers MF476856-MF476874. Outgroups were chosen based on close phylogenetic relationship between taxa (Alencar et al. 2016). Additional genetic material along with our outgroups came from published records in GenBank (see Table 2). We performed maximum-likelihood (ML) analyses on the concatenated mtDNA using RAxML (v8.2.9, Stamatakis, 2014) with the rapid bootstrap inferences (1000 replicates) and subsequent GTRCAT thorough ML search, with each gene as a separate partition. We also conducted Bayesian analyses using MrBayes (v3.2.6; Ronquist et al. 2012). We partitioned our dataset by locus, applied the GTR $+\mathrm{I}+\mathrm{G}$ model, and unlinked all partitions. We ran our analyses for $10 \times 10^{6}$ generations with four chains, sampling every 1000 generations. Stationarity was assessed by the average standard deviation of split frequencies (ASDSF $<0.01$ ) and visual plots of log-likelihood by generation in Tracer v1.2 (Rambaut and Drummond, 2004); the first 1,000 trees (of 10,000) were discarded as the burn-in. A 50\% majority-rule with compatible groups consensus was taken from the remaining trees and posterior probabilities (pp) of 0.95 or above were considered significant.

We examined morphological characters considered diagnostic to the Popeia subgenus based on previous studies (Pope \& Pope, 1933; Regenass \& Kramer, 1981; Vogel et al. 2004). Although the most recent taxonomic treatment of the subgenus Popeia (Wostl et al. 2016) indicated that all Sundaic populations should be recognized as T. sabahi, we only compared the morphology of our specimens to the Thai-Malaysian populations of T. sabahi recognized as T. fucatus by Vogel et al. (2004) (see Table 2). This decision makes it easier for us to compare our specimens on a local basis, as the allopatric populations of T. sabahi defined by Wostl et al. (2016) as well as 
Sanders et al. (2006) each contain relatively stable morphologies, sexual dimorphism and ecology. Ventral scale count methodology follows Dowling (1951). Color pattern vocabulary follows Vogel et al. (2004).

TABLE 1. List of primers used to amplify each mitochondrial gene in our study.

\begin{tabular}{llllll}
\hline Locus & Primer & Direction & Temp. & Sequence 5' to 3' & Reference \\
\hline 12S & 12SI & Forward & 48 & TGCCAGCAGYCGCGGTTA & Puillandre et al. 2009 \\
12S & 12SIII & Reverse & 48 & AGAGYGRCGGGCGATGTGT & Puillandre et al. 2009 \\
16S & 16Sar-L & Forward & 54 & CGCCTGTTTATCAAAAACAT & Palumbi et al. 1991 \\
16S & 16Sbr-H & Reverse & 54 & CCGGTCTGAACTCAGATCACGT & Palumbi et al. 1991 \\
CytB & Gludge & Forward & 48 & TGACTTGAARAACCAYCGTTG & Parkinson et al. 2002; \\
CytB & ATRCB3 & Reverse & 48 & TGAGAAGTTTTCYGGGTCRTT & Parkinson et al. 2002; \\
ND4 & HypLeu2r.1 & Forward & 48 & TACCACTTGGATTTGCACCA & Mulcahy 2008 MPE \\
ND4 & HypNad4f.1 & Reverse & 48 & TGCCTAGCAGCCTTYATAGCTA & Mulcahy 2008 MPE \\
\hline
\end{tabular}

\section{Results}

We obtained alignments of the mitochondrial genes CytB (826 bp), ND4 (846 bp), 16S (539 bp) and 12S (410 bp) for a total of $2621 \mathrm{bp}$ of aligned sequence data. Our ML analyses placed specimens from northern Myanmar sister to T. nebularis, with poor bootstrap value support ( $<50 \%$, Fig. 1). An outlying specimen (B467), from Phang-nga Province, south Thailand, initially identified as T. popeiorum was placed at the base of a clade containing the northern Myanmar T. popeiorum + T. nebularis specimens with strong support (91\%). The latter two were sister to one another, but by a very short branch length with poor support $(<50 \%)$. The Tanintharyi Region and western Thailand specimens (AMB52 and B34 of Sanders et al. 2006) were placed sister to this clade (Fig. 1). However, similar to the taxonomy of Wostl et al. (2016) and Sanders et al. (2006), we recovered a single, well-supported clade containing all Sundaic populations of Popeia with strong support (100\%). Our Bayesian results were very similar, with the main difference being the south Thai sample (B467) was placed sister to T. nebularis clade (albeit with poor posterior probability support and short branch; $<.50 \mathrm{pp}$ ), and they were placed sister to the northern $T$. popeiorum samples, with strong support $(\mathrm{pp}=0.99)$. The $T$. sabahi clade was resolved with strong support $(\mathrm{pp}=$ 0.99), relationships among the lineages in this clade were slightly different from the ML topology, but were also poorly supported (values shown in Fig. 1).

The morphology is summarized in Table 3. All specimens are described as followed: TailL/TotalL ratio $20.9 \%$ in the male, $15.0-17.0 \%$ in females. The dorsal pattern in all specimens was solid green, except for the juvenile specimen (USNM 587920), which had faint irregular vertebral crossbars. It is unclear what color they were in life, but they are dark green in preservative. Postocular striping in females is faint but present in all specimens as a thin white line; in the male (USNM 587921), the postocular streak is bicolored with the thin section (bottom) plain white and the wide section (top) red. Ventrolateral striping in females is extremely faint, less than half a dorsal scale wide, visible as margins on the dorsal scales and is plain white. In the male (USNM 587921), the ventrolateral stripe is bicolored with the bottom being deep red and the top plain white, extending to the tail where it becomes sporadic. The eye color in life (available from photographs of female specimens USNM 587588 and USNM $587919)$ is red. The tail is mottled in rusty-red in all specimens with no clear distinction between the two colors, but females appear to have a green border laterally. Snout truncated; distinct but no sharp canthus rostralis; rostral visible from above; occipital scales distinctively keeled in the male (USNM 587921), slightly keeled in females; temporals only slightly keeled in all specimens. Loreal pit in contact with second labial; nostril always distinct from first labial; two preoculars in contact with loreal pit; single subocular always long and crescent shaped; one or two rows of scales between subocular and supralabials; first infralabial largest; two chin shields; mental never in contact with chin shields. Dorsal scales keeled and in 21 rows at midbody; Ventral scales in females 165-171, 169 in male specimen; subcaudals 57-65 in females, 72 in male specimen, and all have a single anal plate. 


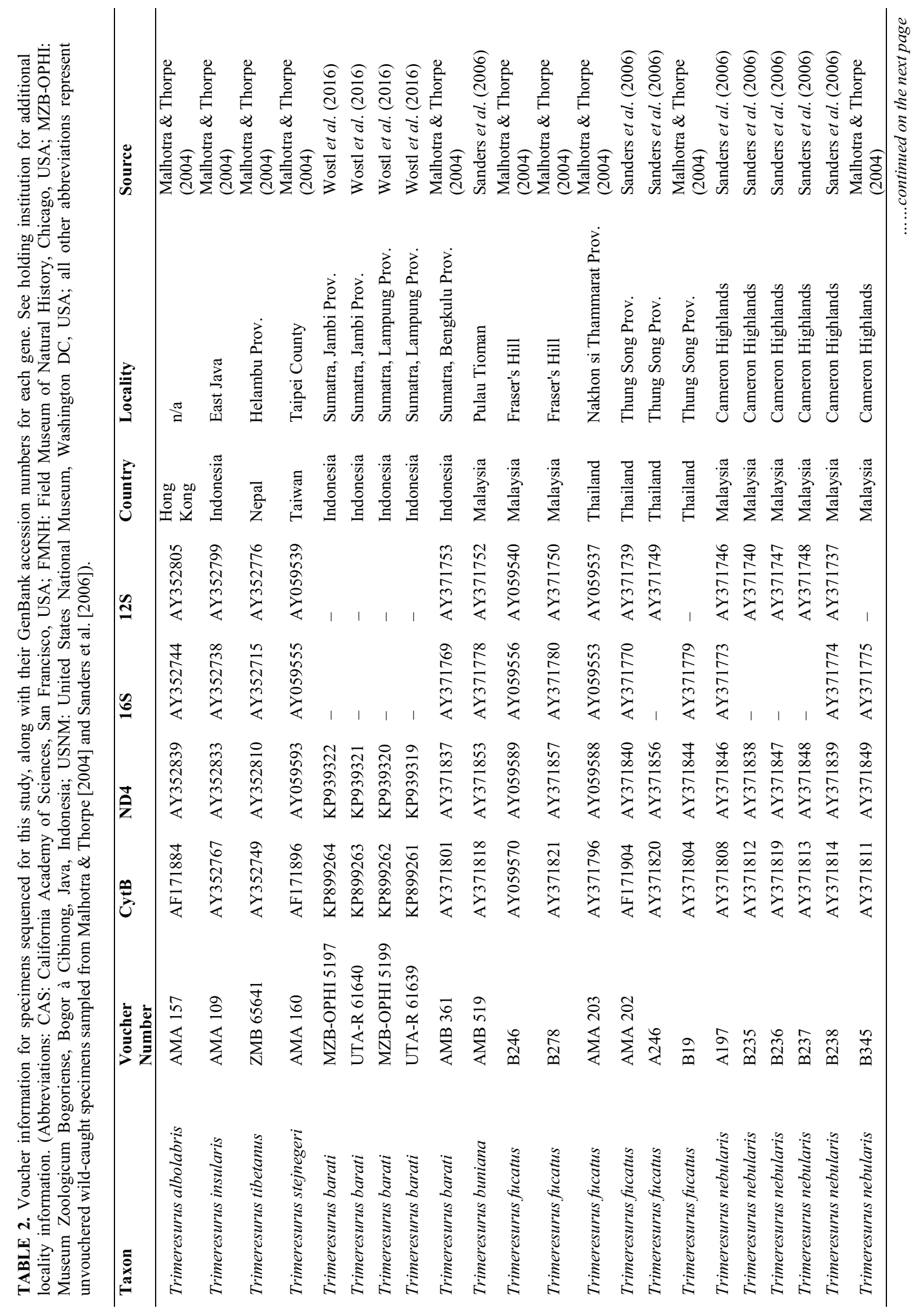




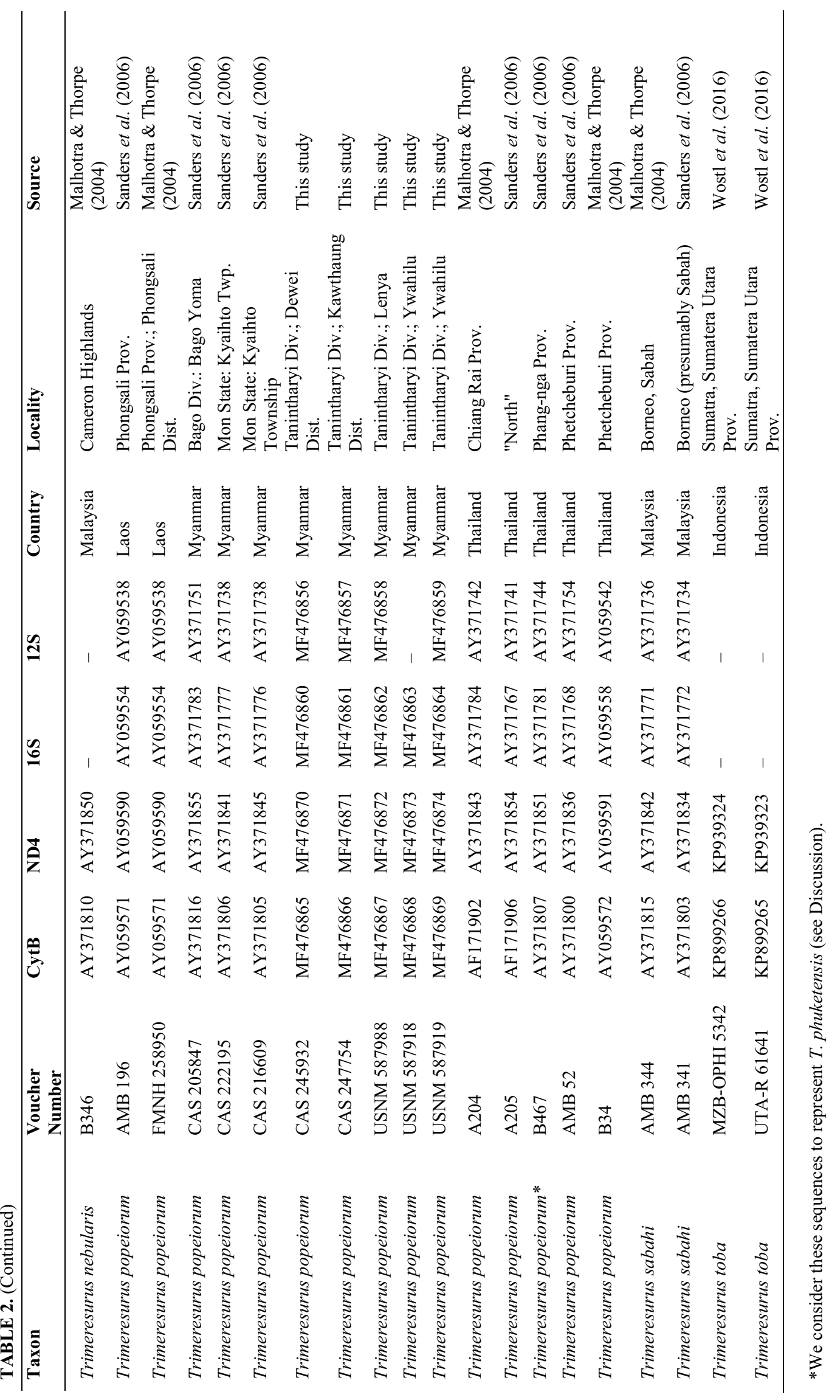




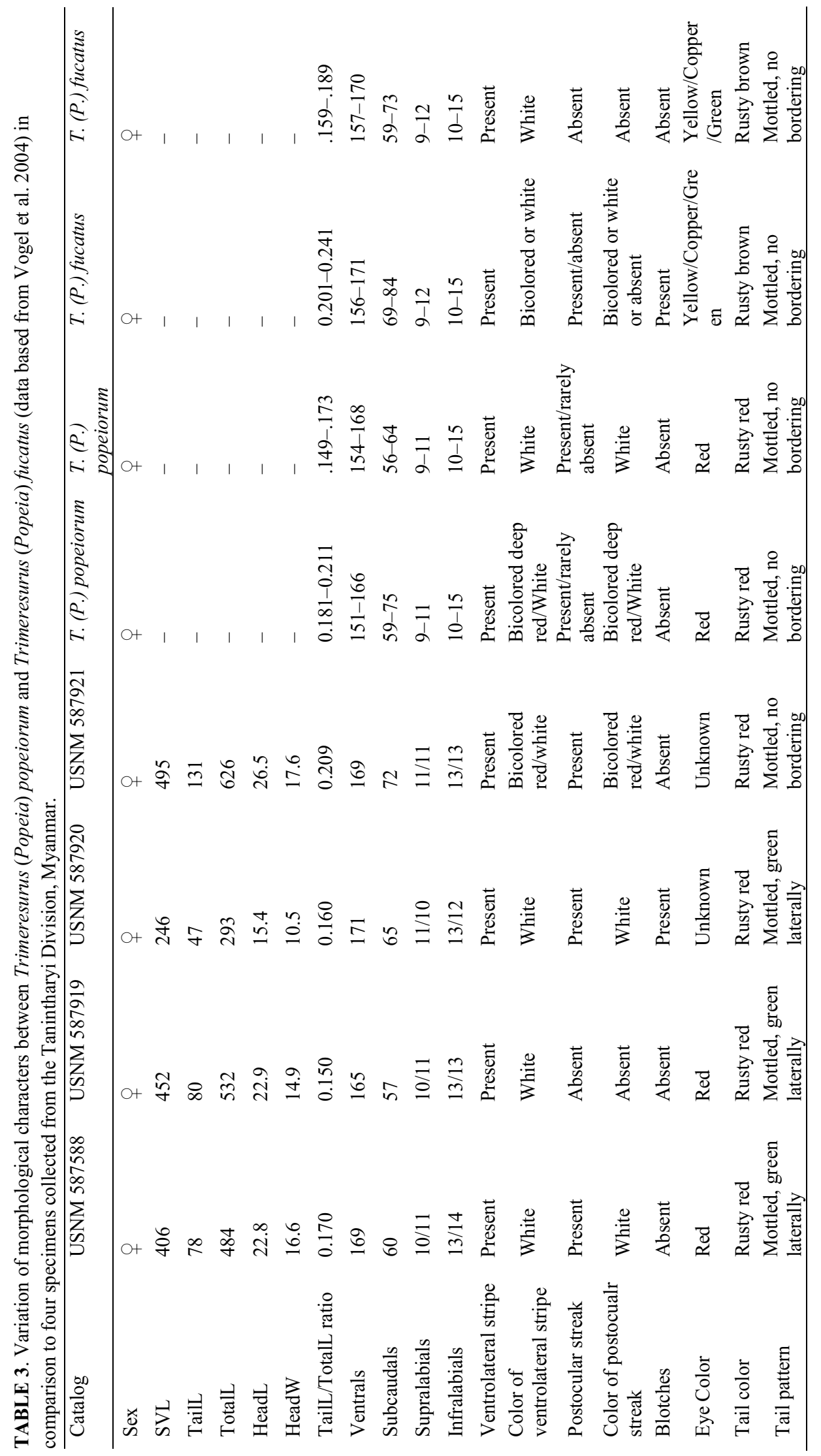




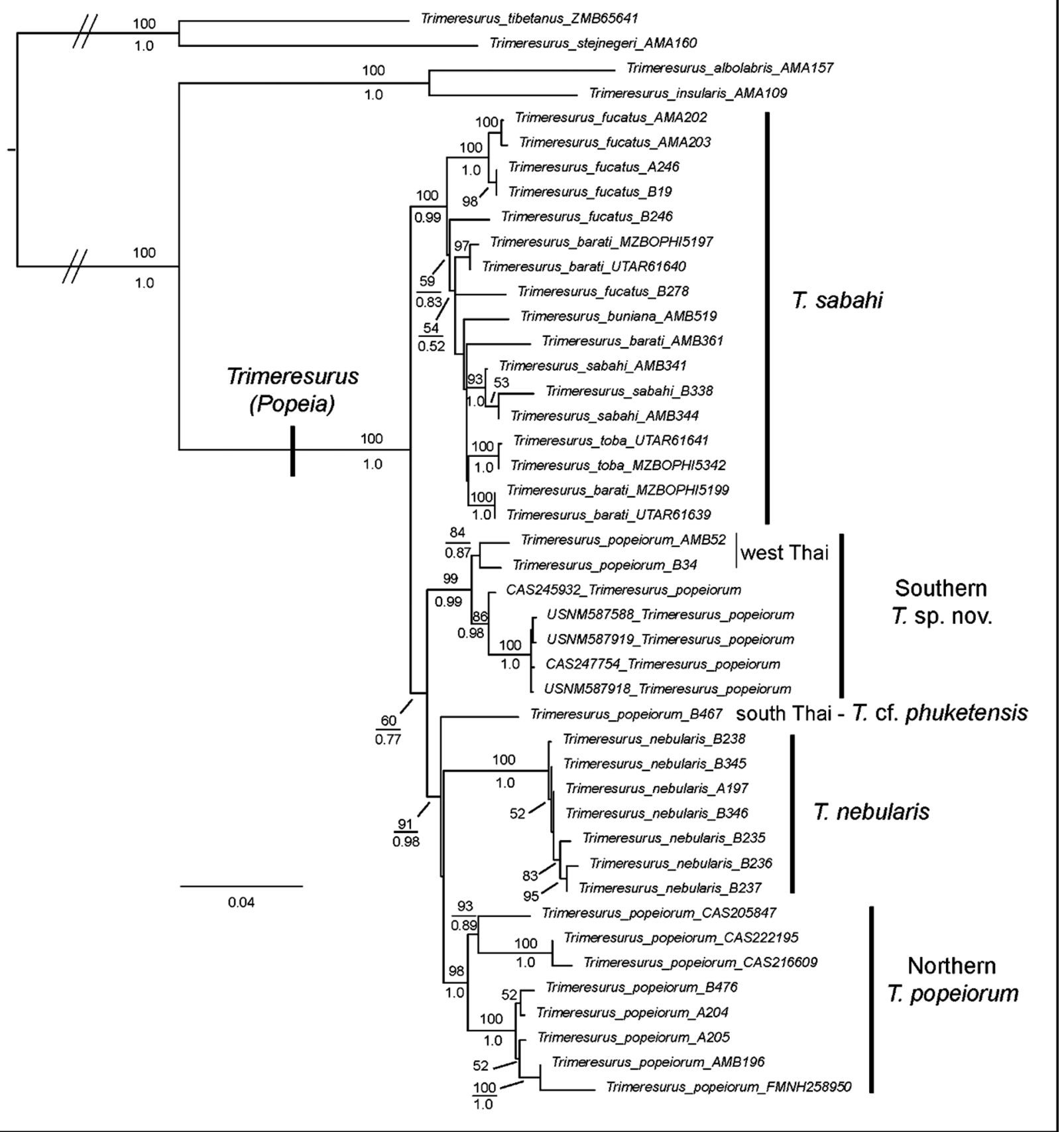

FIGURE 1. Maximum-Likelihood phylogeny of the Trimeresurus (Popeia) subgenus based on 2621 base-pairs of mtDNA from four loci (ND4, CytB, 12S, and 16S). Major clades found are labeled using vertical lines with their designated taxonomy. Maximum-Likelihood bootstrap values are shown above and Bayesian posterior-probabilities are shown below, for relevant nodes.

\section{Discussion}

Species assignment in the subgenus Popeia is challenging because of previous name assignments to specimens do not match their "identity" in molecular phylogenies. For example, the specimen (B467) from Phang-nga Province, Thailand, identified as "Popeia popeiorum" (sensu Sanders et al. 2006), is placed sister to the T. nebularis + northern T. popeiorum populations, which is enigmatic. The sequence data for B467 have no further locality information, nor a voucher specimen. Possibly, it was examined in the field for morphological data and blood 
samples, and was not collected as a voucher. Sumontha et al. (2011) described T. phuketensis from nearby Phuket Province, Thailand, but they did not provide any tissue for a molecular analysis. It is possible that the south Thai sample (B467) represents T. phuketensis, which was not described at the time it was sampled. Presently, $T$. phuketensis is only known from Phuket Island. Recent studies of the agamid lizard Bronchocela rayanesis showed that species, initially described from Langkawi Island, Malaysia (Grismer et al. 2015), also occurs on Phuket Island and mainland Phang-nga Province, Thailand (Grismer et al. 2016; Zug et al. 2017). The tree agamid lizard Acanthosaura phuketensis (Pauwels et al. 2015), also seems to occur on both Phuket Island and nearby adjacent Phang-nga, Province. Until sequences from the type locality of T. phuketensis are analyzed, the status of B467 remains problematic. Our data supports T. phuketensis as valid; and we tentatively identify the sequences of B467 to represent this species.

Most of the Tanintharyi specimens in our dataset are morphologically identical to T. popeiorum. In all females, a faint plain white postocular stripe is always present; adults lack vertebral spots; eye color of specimens photographed in life is deep red. These characters match the descriptions of Vogel et al. (2004). There is some overlap with features of T. fucatus. Most ventral scale counts of the specimens examined are at the high end of $T$. popeiorum. In the juvenile female specimen USNM 587920 for example, the ventral scale count is 171 (which is higher than in both species), the number of subcaudals is higher than T. popeiorum and within the range of $T$. fucatus, and vertebral spots are usually absent in T. popeiorum. In the male (USNM 587921), the number of ventral scales is 169 , higher than the known ventral scale counts of male T. popeiorum (151-166; Vogel et al. 2004). However, the ventral and caudal scale counts in these specimens are not significantly different from T. popeiorum and may represent clinal variation. Similar trends have been reported in other snakes (Mulcahy \& Archibald, 2003; Lee et al. 2016), including pit vipers (Ashton, 2001). We have not located in-life photographs of these specimens or any other specimens from Kawthaung, or field notes documenting coloration. Therefore, characteristics such as eye color, presence of white vertebral spots, and other important characters that diagnose species of the Popeia subgenus, cannot be determined and affect the accuracy of our identification. Nevertheless, all Tanintharyi and the west Thai specimens (AMB52, B34) of Sanders et al. (2006) do not form a clade with any other Popeia in our molecular dataset from the Thai-Malay Peninsula and Indonesia. Instead, they form a well-supported lineage of their own from the Tanintharyi Region and neighboring Thailand that is tentatively $(60 \% \mathrm{ML}$ and $\mathrm{pp}=0.77)$ placed sister to T. nebularis + northern T. popeiorum, + south Thai specimen (B467 of Sanders et al. 2006), the latter sister to T. nebularis + northern T. popeiorum in our ML phylogeny (nested among them in our Bayesian analysis). Our topology is similar to the results of Sanders et al. (2006) and Wostl et al. (2016), both of which also recovered a paraphyletic T. popeiorum with respect to the samples from west Thailand. However, the species T. fucatus in our tree is paraphyletic. This may be because Wostl et al. (2016) only sampled two closely-related T. fucatus (A202-3), and used only two mitochondrial genes, while our phylogenetic analysis used four genes and all available genetic samples.

Herein, our molecular results lead us to consider three possible taxonomic solutions: (A) recognize all clades as a single species-T. popeiorum; (B) consider the two most diverged clades as species-T. popeiorum (including T. nebularis) and T. sabahi; or (C) consider all clades as distinct species. Indeed, solutions A and B are conservative approaches that stabilize the taxonomy of the Popeia subgenus significantly. However, both approaches ignore genetic diversity and distinctiveness of T. nebularis, which, under multiple sources, is morphologically and ecologically distinct (Vogel et al. 2004; Sanders et al. 2006). Because of this, we believe that solution Crecognizing both northern and southern clades of T. popeiorum, as well as T. nebularis, T. phuketensis, and T. sabahi (sensu Sanders et al. 2006 and Wostl et al. 2016) is the most suitable decision. In this case, it may be applicable to recognize the allopatric, yet closely related populations of T. sabahi as subspecies.

Interest in the application of the subspecies designation has been recently discussed within snakes and other reptiles (Mulcahy, 2008; Hawlitschek et al. 2012; Tolstrom et al. 2014; Kaito et al. 2017). Nevertheless, unanimous criteria for the recognition and designation of subspecies in reptiles and amphibians are lacking. While we acknowledge that the assignment of subspecies will likely subside on a case-by-case basis, we offer the following justifications for why we believe designating taxa in the $T$. sabahi clade as subspecies is the appropriate taxonomic decision following similar arguments for the generalized lineage concept and species criteria discussed in Mulcahy (2008). First, all of the previously recognized taxa (T. sabahi, T. fucatus, T. barati, T. buniana and T. toba) are all geographically-cohesive (allopatric) with respect to one another (therefore, likely no current geneflow). The populations do not exhibit intergradation, they are morphologically distinct, yet they are not genetically 


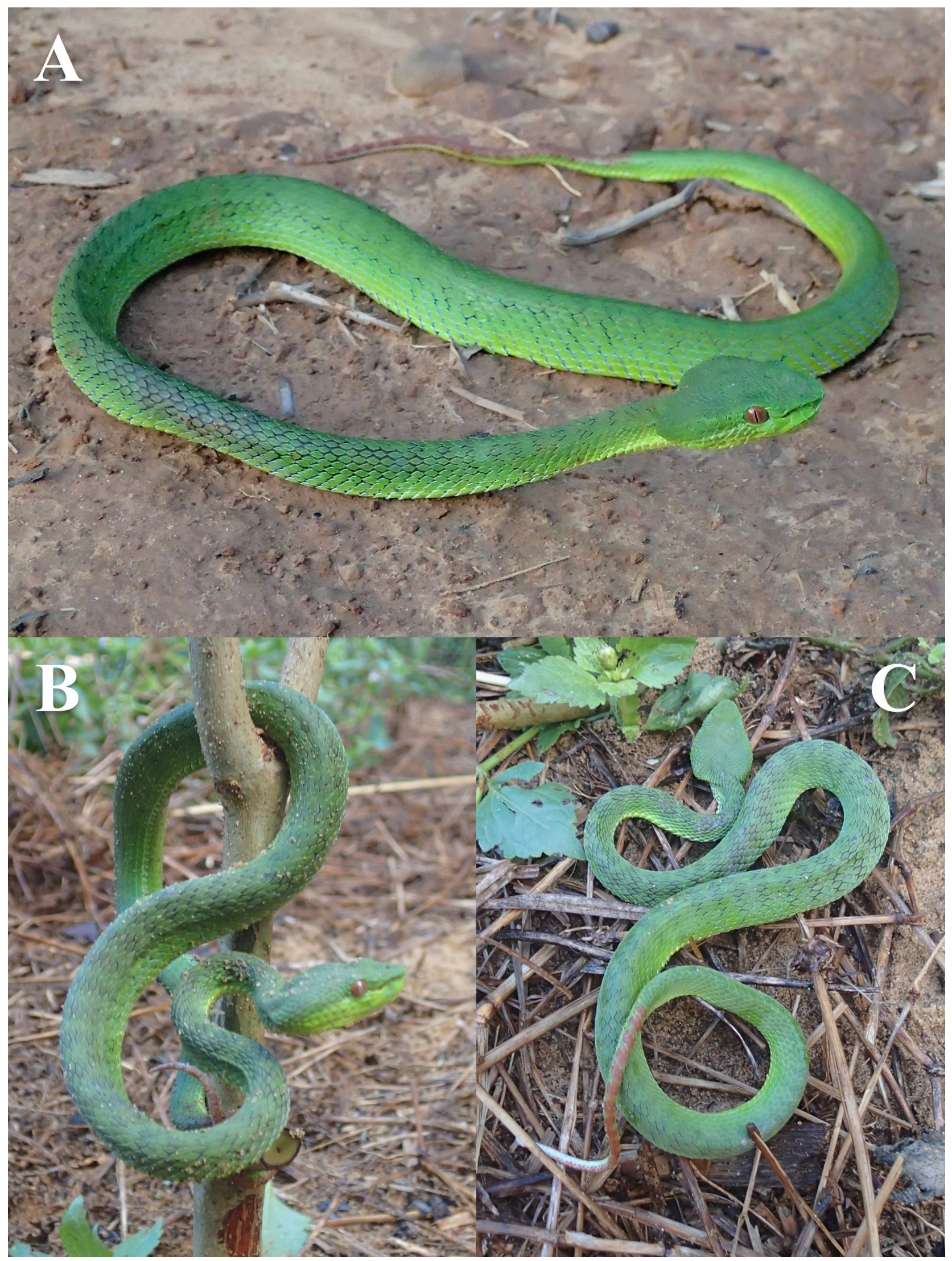

FIGURE 2. Live specimens of Trimeresurus (Popeia) collected from the Tanintharyi Division, Myanmar examined in our study. (A) Adult female specimen of Trimeresurus (Popeia) sp. nov from Lenya, Tanintharyi Division, Myanmar (USNM 587588). (B-C) Adult female specimen of Trimeresurus (Popeia) sp. nov from Ywahilu, Tanintharyi Division, Myanmar (USNM 587919). Photographs by Daniel G. Mulcahy. 


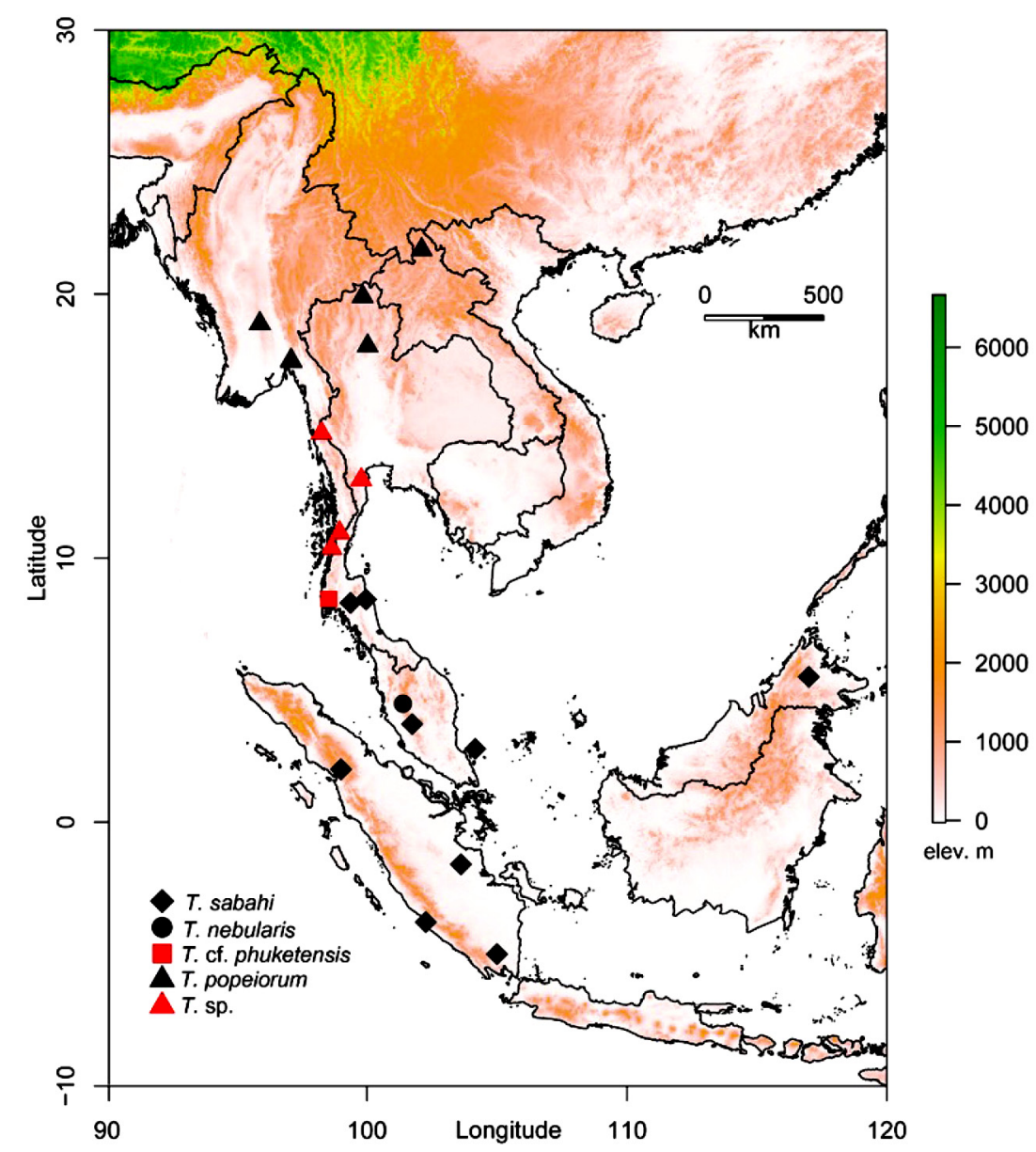

FIGURE 3. Distribution map showing the molecular sampling of Trimeresurus (Popeia) in Southeast Asia. See symbols for species identification.

distinct, which could be caused by incomplete lineage sorting or recent introgression. Regarding the morphological distinctiveness of the Sundaland taxa, Wostl et al. (2016) argued that these populations exhibited minimal morphological differences; however, they only examined a few specimens from Sumatra (five $T$. barati and three $T$. $t o b a$ ), and did not examine comparative material from museum collections. Instead, Wostl et al. (2016) recorded morphological characters from photographs for T. fucatus and T. nebularis and did not account for the sexual dimorphism present in populations referable to T. buniana and T. fucatus. By not recognizing these taxa, one undermines the potential diversity present in this group. The subspecies designation may be of particular importance in T. buniana, endemic to Pulau Tioman, Malaysia, because it is listed as "Endangered" under the IUCN Red List. A flagship species, T. buniana and the island itself are under threat by habitat loss and purchase of the island by a private company. Treating this taxon as a synonym would undermine its conservation status and potentially result in its extinction. Designating this population as a subspecies, will enable it to maintain protection better than conservation management definitions, such as, an evolutionary significant unit (ESU) or management unit (MU), particularly in this case where only one genetic sample is available where monophyly cannot be assessed; see Mulcahy et al. (2006 and references therein) for discussion of terms.

T. popeiorum was described by Smith (1937) without any precise type locality or type specimen. Taylor \& Elbel (1958) corrected this, by designating a lectotype (BMNH 72.4.17.137) with the type locality "Khasi Hills, Assam, [State of Meghalaya], India". Since the specimens from the northern clade (from northern Myanmar, Thailand and Laos) are closest to the type locality, we assign T. popeiorum sensu stricto to the northern clade. The southern clade has significant genetic distance from the northern clade and is restricted to a distinct geographic area (Tanintharyi, Myanmar and western Thailand). Therefore, it is likely that these populations represent a cryptic, yet 
undescribed species. Recent studies focusing on the Isthmus of Kra region of Myanmar and Thailand have discovered several endemic reptile species (Vogel et al. 2012; Pauwels et al. 2016; Zug et al. 2017; Connette et al. 2017). As yet, we have discovered no diagnostic character that separates the northern clade of T. popeiorum from the southern one. Cryptic species that are molecularly distinct yet morphologically similar may sometimes be the result of a poor morphological effort (Grismer et al. 2014). Furthermore, datasets for pit vipers may suffer from issues such as introgression and incomplete lineage sorting (Guo et al. 2015). Although we contend that the populations of the southern clade are cryptic, we refrain from formally describing it as our sample size is limited and prevents us from preparing a formal taxonomic description. Instead, we prefer to wait for a study that addresses these issues by incorporating nuclear DNA (preferably RadSeq or UCE; e.g. Leaché et al. 2015), additional morphological characters, and new material from potential sampling gaps. Until then, we refer to the populations representing the southern clade as Trimeresurus (Popeia) sp. nov.

In conclusion, we suggest researchers studying the herpetofauna of Southeast Asia continue to investigate the subgenus Popeia and to obtain more specimens from this region to allow for morphometric analyses. The possibility of an undescribed species in Malaysia (Sumarli et al. 2015) also suggests that the systematics of this group are still unresolved. A study that incorporates our samples with other newly collected material, along with additional morphological characters and nuclear DNA will hopefully provide a more insightful look at the phylogenetic relationships of the Popeia subgenus and resolve debates surrounding recent systematic interpretations within this group. We recommend the use of subspecies in the T. sabahi complex, recognizing the following taxa within the Popeia subgenus: Trimeresurus sp. nov, (Mulcahy et al. 2017), Trimeresurus popeiorum (Smith, 1937), Trimeresurus nebularis (Vogel, David and Pauwels, 2004), Trimeresurus phuketensis (Sumontha, Kunya, Pauwels, Nitikul, Punnadee, 2011), Trimeresurus sabahi sabahi (Regenass \& Kramer, 1981), Trimeresurus sabahi barati (Regenass \& Kramer, 1981), Trimeresurus sabahi buniana (Grismer, Grismer \& McGuire, 2006), Trimeresurus sabahi fucatus (Vogel, David \& Pauwels, 2004), and Trimeresurus sabahi toba (David, Petri, Vogel \& Doria, 2009).

\section{Acknowledgements}

We thank Frank Momberg and Mark Grindley of Fauna \& Flora International (FFI) for funding and supporting our expeditions to the Tanintharyi Region, and in particular Myint Kyaw Thura and Thaw Zin for field assistance. We thank Steve W. Gotte, Kenneth Tighe, Addison Wynn and Jeremy Jacobs, National Museum of Natural History (USNM) for their assistance. We also thank James B. Murphy and Joseph Mendelson III for their constructive reviews of this manuscript, as well as Gernot Vogel, Patrick David and Lee Grismer for discussions on the taxonomy of the Popeia subgenus. Portions of the laboratory and/or computer work were conducted in and with the support of the Laboratories of Analytical Biology facilities (NMNH) or its partner labs, and lab work was funded by the Global Genome Initiative (NMNH) and lab work was assisted by L. Dickens Jr., A. Ibarra, and B. Cruz of the Youth Engagement thru Science Global Genome (YES!-GG) Program. Additional funding for the Smithsonian field team derived from the Smithsonian Myanmar Biodiversity Initiative and its support by The Leona M. and Harry B. Helmsley Charitable Trust awarded to Melissa Songer (Smithsonian Conservation Biology Institute).

\section{Literature cited}

Ashton, K.G. (2001) Body size variation among mainland populations of the western rattlesnake (Crotalus viridis). Evolution, 55 (12), 2523-2533.

Bickford, D., Lohman, D.J., Sodhi, N.S., Ng, P.K., Meier, R., Winker, K., Ingram, K.K. \& Das, I. (2007) Cryptic species as a window on diversity and conservation. Trends in Ecology \& Evolution, 22 (3), 148-155. https://doi.org/10.1016/j.tree.2006.11.004

Connette, G.M., Oswald, P., Thura, M.K., Connette, K.J.L., Grindley, M.E., Songer, M., Zug, G. R. \& Mulcahy, D.G. (2017) Rapid forest clearing in a Myanmar proposed national park threatens two newly discovered species of geckos (Gekkonidae: Cyrtodactylus). PloS one, 12 (4), e0174432. https://doi.org/10.1371/journal.pone.0174432

David, P., Petri, M., Vogel, G. \& Doria, G. (2009) A new species of pitviper of the genus Trimeresurus (Popeia) from northern Sumatra (Reptilia, Squamata, Viperidae). Annali del Museo Civico di Storia Naturale «G. Doria, Genova, 100, 323-346. 
David, P., Vogel, G. \& Dubois, A. (2011) On the need to follow rigorously the Rules of the Code for the subsequent designation of a nucleospecies (type species) for a nominal genus which lacked one: the case of the nominal genus Trimeresurus Lacépède, 1804 (Reptilia: Squamata: Viperidae). Zootaxa, 2992 (1), 1-51.

David, P., Vogel, G., Vijayakumar, S.P. \& Vidal, N. (2006) A revision of the Trimeresurus puniceus-complex (Serpentes: Viperidae: Crotalinae) based on morphological and molecular data. Zootaxa, 1293, 1-80

Funk, W.C., Caminer, M. \& Ron, S.R. (2012) High levels of cryptic species diversity uncovered in Amazonian frogs. Proceedings of the Royal Society B, Biological Sciences, 279, 1806-1814. https://doi.org/10.1098/rspb.2011.1653

Giannasi, N.C., Thorpe, R.S. \& Malhotra, A. (2001) The use of amplified fragment length polymorphism AFLP in determining species trees at fine taxonomic levels: analysis of a medically important snake, Trimeresurus albolabris. Molecular Ecology, 10, 419-426. https://doi.org/10.1046/j.1365-294X.2001.01220.x

Grismer, L.L., Grismer, J.L. \& McGuire, J.A. (2006) A new species of pitviper of the genus Popeia (Squamata: Viperidae) from Pulau Tioman, Pahang, West Malaysia. Zootaxa, 1305, 1-19.

Grismer, L.L., Wood Jr., P.L., Anuar, S., Mohd., M.A., Quah, E.S.H., McGuire, J.A., Brown, R. M., Ngo, V.T. \& Hong, P. (2014c) Integrative taxonomy uncovers high levels of cryptic species diversity in Hemiphyllodactylus Bleeker, 1860 (Squamata: Gekkonidae) and the description of a new species from Peninsular Malaysia. Zoological Journal of the Linnean Society, 169, 849-880. https://doi.org/10.1111/zoj.12064

Grismer, L.L., Wood, P.L., Aowphol, A., Cota, M., Murdoch, M.L., Aguilar, C. \& Grismer, M. S. (2016) Taxonomy, phylogeny, and distribution of Bronchocela rayaensis (Squamata: Agamidae) on the Thai-Malay Peninsula. Zootaxa, 4092 (3), 414. https://doi.org/10.11646/zootaxa.4092.3.6

Grismer, L.L., Wood Jr, P.L., Lee, C.H., Quah, E.S.H., Anuar, S., Ngadi, E. \& Sites Jr, J.W. (2015) An integrative taxonomic review of the agamid genus Bronchocela (Kuhl, 1820) from Peninsular Malaysia with descriptions of new montane and insular endemics. Zootaxa, 3948 (1), 1-23.

https://doi.org/10.11646/zootaxa.3948.1.1

Guo, P., Liu, Q., Zhong, G., Zhu, F., Yan, F., Tang, T., Xiao, R., Fang, M., Wang, P. \& Fu, X. (2015) Cryptic diversity of green pitvipers in Yunnan, South-west China (Squamata, Viperidae). Amphibia-Reptilia, 36 (3), 265-276. https://doi.org/10.1163/15685381-00003004

Guo, P., Malhotra, A., Li, C., Creer, S., Pook, C.E. \& Wen, T. (2009) Systematics of the Protobothrops jerdonii complex (Serpentes, Viperidae, Crotalinae) inferred from morphometric data and molecular phylogeny. The Herpetological Journal, 19 (2), 85-96.

Guo, P. \& Wang, Y.Z. (2011) A new genus and species of cryptic Asian green pitviper (Serpentes: Viperidae: Crotalinae) from southwest China. Zootaxa, 2918, 1-14.

Hawlitschek, O., Nagy, Z.T. \& Glaw, F. (2012) Island evolution and systematic revision of Comoran snakes: why and when subspecies still make sense. PLoS One, 7 (8), e42970. https://doi.org/10.1371/journal.pone.0042970

Hebert, P.D., Penton, E.H., Burns, J.M., Janzen, D.H. \& Hallwachs, W. (2004) Ten species in one: DNA barcoding reveals cryptic species in the neotropical skipper butterfly Astraptes fulgerator. Proceedings of the National Academy of Sciences of the United States of America, 101 (41), 14812-14817. https://doi.org/10.1073/pnas.0406166101

Jörger, K.M. \& Schrödl, M. (2013) How to describe a cryptic species? Practical challenges of molecular taxonomy. Frontiers in Zoology, 10 (1), 59. https://doi.org/10.1186/1742-9994-10-59

Kaito, T., Ota, H. \& Toda, M. (2017) The evolutionary history and taxonomic reevaluation of the Japanese coral snake, Sinomicrurus japonicus (Serpentes, Elapidae), endemic to the Ryukyu Archipelago, Japan, by use of molecular and morphological analyses. Journal of Zoological Systematics and Evolutionary Research, 55 (2), 156-166. https://doi.org/10.1111/jzs.12162

Leaché, A.D., Chavez, A.S., Jones, L.N., Grummer, J.A., Gottscho, A.D. \& Linkem, C.W. (2015) Phylogenomics of phrynosomatid lizards: conflicting signals from sequence capture versus restriction site associated DNA sequencing. Genome Biology and Evolution, 7 (3), 706-719. https://doi.org/10.1093/gbe/evv026

Lee, J.L., Thompson, A. \& Mulcahy, D.G. (2016) Relationships between Numbers of Vertebrae, Scale Counts, and Body Size, with Implications for Taxonomy in Nightsnakes (Genus: Hypsiglena). Journal of Herpetology, 50 (4), 616-620. https://doi.org/10.1670/15-066

Lee, J.L., Thura, M.K., Mulcahy, D.G. \& Zug, G.R. (2015) Three Colubrid Snakes New to Myanmar. Herpetology Notes, 8, 217-220.

Loredo, A.I., Wood Jr, P.L., Quah, E.S.H., Anuar, S.H., Greer, L., Norhayati, A. \& Grismer, L. L. (2013) Cryptic speciation within Asthenodipsas vertebralis (Boulenger, 1900) (Squamata: Pareatidae), the description of a new species from Peninsular Malaysia, and the resurrection of A. tropidonotus (Lidth de Jude, 1923) from Sumatra: an integrative taxonomic analysis. Zootaxa, 3664 (4), 505-524. 
https://doi.org/10.11646/zootaxa.3664.4.5

Malhotra, A. \& Thorpe, R.S. (2000) A phylogeny of the Trimeresurus group of pitvipers: new evidence from a mitochondrial gene tree. Molecular Phylogenetics and Evolution, 16, 199-211. https://doi.org/10.1006/mpev.2000.0779

Malhotra, A. \& Thorpe, R.S. (2004) A phylogeny of four mitochondrial gene regions suggests a revised taxonomy for Asian pitvipers (Trimeresurus and Ovophis). Molecular Phylogenetics and Evolution, 32, 83-100. https://doi.org/10.1016/j.ympev.2004.02.008

Malhotra, A., Thorpe, R.S. \& Stuart, B.L. (2011) Two new species of pitviper of the genus Cryptelytrops Cope 1860 (Squamata: Viperidae: Crotalinae) from Southeast Asia. Zootaxa, 2757 (1), 1-23.

Mulcahy, D.G. (2008) Phylogeography and species boundaries of the western North American Nightsnake (Hypsiglena torquata): revisiting the subspecies concept. Molecular Phylogenetics and Evolution, 46 (3), 1095-1115. https://doi.org/10.1016/j.ympev.2007.12.012

Mulcahy, D.G. \& Archibald, M.A. (2003) Geographic variation in the Baja California Nightsnake (Eridiphas slevini), with comments on taxonomy and diet. Journal of Herpetology, 37 (3), 566-571. https://doi.org/10.1670/203-02N

Mulcahy, D.G., Spaulding, A., Mendelson, J.R. \& Brodie Jr., E.D. (2006) Phylogeography of the Flat-tailed Horned lizard (Phrynosoma mcallii) and systematics of the P. mcallii-platyrhinos mtDNA complex. Molecular Ecology, 15 (7), 18071826. https://doi.org/10.1111/j.1365-294X.2006.02892.x

Orlov, N. \& Helfenberger, N. (1997) New mountain species of Trimeresurus (Serpentes, Viperidae, Crotalinae) of the "green" pitvipers group from the Himalayas. Russian Journal of Herpetology, 4, 195-197.

Palumbi, S.R., Martin, A., Romano, S., McMillan, W.O., Stice, L. \& Grabawski G. (1991). The simple fool's guide to PCR, version 2.0. University of Hawaii, Honolulu: Privately published, compiled by Palumbi, S.

Parkinson, C.L., Campbell, J.A. \& Chippindale, P.T. (2002) Multigene phylogeneitc analyses of pitvipers with comments on the biogeographical histroy of the group. In: Schuett, G.W., Höggren, M., Douglas, M.E \& Greene, H.W. (Eds.), Biology of Vipers. Eagle Mountain Publishing, Salt Lake City, UT, 93-110.

Pauwels, O.S.G. \& Chan-ard, T. (2006) Reptiles of Kaeng Krachan National Park, Western Thailand. Natural History Bulletin of the Siam Society, 54 (1), 89-108.

Pauwels, O.S.G., Chan-ard, T., Wanchai, P., Kheowyoo, B. \& Bauer, A.M. (2009) Reptile diversity of Phetchaburi Province, western Thailand: an update. Hamadryad, 34 (1), 9-21.

Pauwels, O.S.G., David, P., Chimsunchart, C. \& Thirakhupt, K. (2003) Reptiles of Phetchaburi Province, Western Thailand: a list of species, with natural history notes, and a discussion on the biogeography at the Isthmus of Kra. The Natural History Journal of Chulalongkorn University, 3 (1), 23-53.

Pauwels, O.S.G., Sumontha, M. \& Bauer, A.M. (2016) A new Bent-toed Gecko (Squamata: Gekkonidae: Cyrtodactylus) from Phetchaburi Province, Thailand. Zootaxa, 4088 (3), 409-419. https://doi.org/10.11646/zootaxa.4088.3.6

Pauwels, O.S.G., Sumontha, M., Kunya, K., Nitikul, A., Samphanthamit, P., Wood Jr, P.L. \& Grismer, L.L. (2015) Acanthosaura phuketensis (Squamata: Agamidae), a new long-horned tree agamid from southwestern Thailand. Zootaxa, 4020 (3), 473-494. https://doi.org/10.11646/zootaxa.4020.3.4

Puillandre, N., Strong, E.E., Bouchet, P., Boisselier, M.C., Couloux, A. \& Samadi, S. (2009) Identifying gastropod spawn from DNA barcodes: possible but not yet practicable. Molecular Ecology Resources, 9 (5), 1311-1321. https://doi.org/10.1111/j.1755-0998.2009.02576.x

Regenass, U. \& Kramer, E. (1981) Zur Systematik der grunen Grubenottern der Gattung Trimeresurus Serpentes, Crotalidae. Revue Suisse de Zoologie, 88 (1), 163-205. https://doi.org/10.5962/bhl.part.82363

Ronquist, F., Teslenko, M., Mark, P.V.D., Ayres, D., Darling, A., Hohna, S., Larget, B., Liu, L., Suchard, M.A. \& Huelsenbeck, J.P. (2012) MrBayes 3.2: efficient Bayesian phylogenetic inference and model choice across a large model space. Systematic Biology, 61 (3), 539-542. https://doi.org/10.1093/sysbio/sys029

Sanders, K.L., Malhotra, A. \& Thorpe, R.S. (2006) Combining molecular, morphological and ecological data to infer species boundaries in a cryptic tropical pitviper. Biological Journal of the Linnean Society, 87 (3), 343-364. https://doi.org/10.1111/j.1095-8312.2006.00568.x

Smith, M.A. (1937) The names of two indian vipers. Journal of the Bombay Natural History Society, 39, 730-731

Sumarli, A.X., Grismer, L.L., Anuar, S., Muin, M.A. \& Quah, E.S.H. (2015) First report on the amphibians and reptiles of a remote mountain, Gunung Tebu in northeastern Peninsular Malaysia, Check List, 11 (4), 1679. https://doi.org/10.15560/11.4.1679

Sumontha, M., Kunya, K., Pauwels, O.S.G., Nitikul, A. \& Punnadee, S. (2011) Trimeresurus (Popeia) phuketensis, a new pitviper (Squamata: Viperidae) from Phuket island, southwestern Thailand, Russian Journal of Herpetology, 18 (3), 185 194.

Thorpe, R.S., Creer, S., Lallias, D., Dawnay, L., Stuart, B.L. \& Malhotra, A. (2015) Convergence of multiple markers and 
analysis methods defines the genetic distinctiveness of cryptic pitvipers. Molecular Phylogenetics and Evolution, 92, 266279.

https://doi.org/10.1016/j.ympev.2015.06.001

Torstrom, S.M., Pangle, K.L. \& Swanson, B.J. (2014) Shedding subspecies: the influence of genetics on reptile subspecies taxonomy. Molecular Phylogenetics and Evolution, 76, 134-143.

https://doi.org/10.1016/j.ympev.2014.03.011

Woodruff, D.S. (2010) Biogeography and conservation in Southeast Asia: how 2.7 million years of repeated environmental fluctuations affect today's patterns and the future of the remaining refugial-phase biodiversity. Biodiversity and Conservation, 19 (4), 919-941. https://doi.org/10.1007/s10531-010-9783-3

Wostl, E., Sidik, I., Trilaksono, W., Shaney, K.J., Kurniawan, N. \& Smith, E.N. (2016) Taxonomic Status of the Sumatran Pitviper Trimeresurus (Popeia) toba David, Petri, Vogel \& Doria, 2009 (Squamata: Viperidae) and Other Sunda Shelf Species of the Subgenus Popeia. Journal of Herpetology, 50 (4), 633-641. https://doi.org/10.1670/15-045

Vogel, G., David, P. \& Chandramouli, S.R. (2014) On the systematics of Trimeresurus labialis Fitzinger in Steindachner, 1867 , a pitviper from the Nicobar Islands (India), with revalidation of Trimeresurus mutabilis Stoliczka, 1870 (Squamata, Viperidae, Crotalinae). Zootaxa, 3786 (5), 557-573.

Vogel, G., David, P. \& Pauwels, O.S.G. (2004) A review of morphological variation in Trimeresurus popeiorum (Serpentes: Viperidae: Crotalinae), with the description of two new species. Zootaxa, (727), 1-61.

Vogel, G., David, P. \& Sidik, I. (2014) On Trimeresurus sumatranus (Raffles, 1822), with the designation of a neotype and the description of a new species of pitviper from Sumatra (Squamata: Viperidae: Crotalinae). Amphibian \& Reptile Conservation, 8 (2), 1-29 (e80).

Vogel, G., Van Rooijen, J. \& Hauser, S. (2012) A new species of Dendrelaphis Boulenger, 1890 (Squamata: Colubridae) from Thailand and Myanmar. Zootaxa, 3392 (1), 35-46.

Zug, G.R., Mulcahy, D.G. \& Vindum, J.V. (2017) Resurrection of Bronchocela burmana Blanford, 1878 for the Green Crested Lizard (Squamata, Agamidae) of southern Myanmar. ZooKeys, 657, 141-156.

https://doi.org/10.3897/zookeys.657.11600 